\title{
Inflation Forecasting, Relative Price Variability and Skewness
}

\author{
Jane M. Binner* \\ Aston University \\ Thomas Elger \\ Lund University \\ Barry E. Jones \\ SUNY Binghamton \\ Birger Nilsson \\ Lund University
}

\begin{abstract}
This paper presents out-of-sample inflation forecasting results based on relative price variability and skewness. It is demonstrated that forecasts on long horizons of 1.5-2 years are significantly improved if the forecast equation is augmented with skewness.
\end{abstract}

JEL: E17, E31, C43

Keywords: inflation forecasting, relative price variability, relative price skewness

${ }^{*}$ Corresponding author. Economics and Strategy Group, Aston Business School, Aston University, Aston Triangle, Birmingham B4 7ET, U.K. Telephone: 0121204 3036. Fax: 0121204 3306. Email: j.m.binner@aston.ac.uk 


\section{Introduction}

The relationship between inflation and the variability and the skewness of changes in relative prices has given rise to an extensive theoretical and empirical literature.

Theoretical models that predict a positive (non-causal) relationship between inflation and the variability of price changes include the multi-market extensions of the Lucas (1972, 1973) model by Barro (1976) and Cukierman (1983). Further, Fischer (1981) discusses a Tobin (1972) type model for the goods market that predicts a positive causal relationship running from the variability of changes in prices to inflation. On the other hand, menu-cost models (e.g. Sheshinski \& Weiss, 1977) and contract models (e.g. Bordo, 1980) predict a positive causal relationship in the opposite direction. ${ }^{1}$

Several models predict a positive causal relationship from the skewness of price changes to inflation. Ball \& Mankiw (1995) derive and empirically evaluate a theory of supply shocks based on menu costs. In their model, aggregate inflation is affected if the distribution of supply shocks is skewed and firms adjust their prices only if the shock is large enough. Balke \& Wynne (2000) demonstrate that the same result can be obtained in a model with flexible prices and input-output linkages across sectors. The empirical results in Ball \& Mankiw (1995) are questioned on statistical grounds by Bryan \& Cecchetti (1999). They argue that the documented positive correlation is merely a statistical artifact suffering from a small sample bias problem.

This paper contributes to the literature by investigating the usefulness of second and third moments for out-of-sample inflation forecasting purposes. The forecasting method advocated in this paper allows for time-varying higher moments but avoids the difficulty of

\footnotetext{
${ }^{1}$ Vining \& Elwertowski (1976) and Parks (1978) contain empirical evidence on the (non-causal) relationship between inflation and price variability. Kücük \& Tuğer (2004) survey the models discussed in this paragraph.
} 
forecasting moments. The method follows, in spirit, Stock \& Watson (1999) and Marcellino et al. (2006).

Our study uses disaggregated quarterly UK consumption data from 1964:1 to 2004:3. A major finding in our analysis is that forecasts on long horizons of 1.5-2 years are significantly improved if a measure of skewness is incorporated into the forecast equation. In contrast, the inclusion of relative price variability leads to deterioration in forecast performance.

\section{Inflation, Relative Price Variability and Skewness}

Divisia indexes are commonly used by statistical agencies as well as practitioners to produce aggregate price and quantity measures. Such indexes are appealing both since they have a functional form that is easy to interpret and since they have known approximation abilities. In this section, we follow Theil (1967) and show how the Divisia price index in each period can be interpreted as the first moment of what Parks $(1978$, p. 80$)$ refers to as the distribution of relative price changes. We also show how second and third moments associated with this distribution can be obtained.

Let $Q_{i t}$ be the quantity of an elementary good $i$ at time $t$ and let $P_{i t}$ denote the price associated with that quantity. There are $n$ elementary goods and the period $t$ expenditure share for good $i$ is $W_{i t}=P_{i t} Q_{i t} / \sum_{j=1}^{n} P_{j t} Q_{j t} . W_{i t}^{*}=\left(W_{i t}+W_{i t-1}\right) / 2$ is the average expenditure share between periods $t$ and $t-1$.

Let $D$ denote the log-change operator such that $D z_{t}=\ln \left(Z_{t}\right)-\ln \left(Z_{t-1}\right)$. The formula for the Divisia price index in log-change form is:

$$
D p_{t}=\sum_{i=1}^{n} W_{i t}^{*} D p_{i t}
$$


Theil (1967) discovered that the Divisia index has a useful stochastic interpretation. He noted that since $\sum_{i=1}^{n} W_{i t}^{*}=1$ and $W_{i t}^{*} \geq 0$, the weights may be regarded as probabilities and the price index in (1) can be interpreted as the first moment of a probability distribution. ${ }^{2}$ The interpretation of the weights as probabilities makes the calculation of second and third moments straightforward:

$$
\begin{aligned}
& \operatorname{var}\left(D p_{t}\right)=\sum_{i=1}^{n} W_{i t}^{*}\left(D p_{i t}-D p_{t}\right)^{2}, \\
& \operatorname{skew}\left(D p_{t}\right)=\sum_{i=1}^{n} W_{i t}^{*}\left(D p_{i t}-D p_{t}\right)^{3} .
\end{aligned}
$$

In the above equations, the term $D p_{i t}-D p_{t}$ measures the rate of change in the $i^{\text {th }}$ relative price, $P_{i t} / P_{t}$ (Parks, 1978, p. 82). Theil (1967, p. 155) notes that the variability measure in (2a) is "a convenient measure for the dispersion of the individual changes [in prices] around their mean". We follow Parks $(1978$, p. 81$)$ and refer to it as "relative price variability" in the remainder of this paper. Accordingly, we refer to the skewness measure in (2b) as relative price skewness.

\section{Forecasting with Moments}

The standard method to obtain multi-period forecasts of macroeconomic time-series is forward iteration. An alternative approach that does not require forward iteration is to directly construct multi-period forecasts based on horizon-specific models. A main argument for the direct approach is that it reduces the problem of a misspecified underlying time-series model. It should be noted, however, that if the underlying model is correctly specified, efficiency is lost because not all information is used. Marcellino et al. (2006) discuss the relative merits of

\footnotetext{
${ }^{2}$ The wording in this paragraph follows Barnett and Serletis (1990) closely. They provide further insights about the stochastic interpretation of the Divisia index.
} 
iterated and direct inflation forecasts and argue that which approach is best is an empirical matter.

In this paper, all conditional forecasts of inflation are obtained using the following direct forecast equation:

$E_{t}\left[D p_{t+h}\right]=\alpha_{0 h t}+\sum_{\ell=1}^{k} \alpha_{\ell h t} D p_{t-\ell+1}+\sum_{\ell=1}^{k} \boldsymbol{\beta}_{\ell h t}^{\prime} \mathbf{X}_{t-\ell+1}$.

In this equation, $h$ is the forecast horizon, $k$ is the number of lags, $\alpha_{0 h t}, \alpha_{\ell h t}$, and $\boldsymbol{\beta}_{\ell h t}$ are estimated parameters, and $\mathbf{X}_{t}$ are the period $t$ moments. The time subscript of the parameters indicates that they are estimated using all available information up to and including time $t$.

A convenient feature of the direct forecast approach in (4) is that it enables us to generate $t+h$ forecasts using only observed data, thus eliminating the need to forecast second and third moments.

\section{Data and Method}

We obtained UK national level final consumption expenditure data from the Office for National Statistics webpage (www.statistics.gov.uk). The full data-set comprises 108 disaggregated time series of personal expenditure on goods and services in current and real terms covering 1964:1 to $2004: 3$, facilitating the calculation of implicit price deflators. ${ }^{3}$ The data is described in detail in the 2004:3 issue of Consumer Trends (www.statistics.gov.uk).

Quarterly inflation is depicted in Figure 1 together with relative price variability, relative price skewness and variability multiplied by skewness.

\footnotetext{
${ }^{3}$ The recorded expenditure flow is zero on one or more occasions in 9 of these 108 series. They have, subsequently, been deleted from our data set.
} 


\section{[FIGURE 1 ABOUT HERE]}

To evaluate the usefulness of second and third moments for inflation forecasting, we reserve the last 10 years of data (1994:4-2004:3) for out-of-sample forecast evaluation. This means that we initially estimate the parameters of the forecast equation (4) using data over 1964:2-1994:3. The parameters are subsequently updated as the information window expands. In the empirical analysis, we consider models based on 1-8 lags and consider forecast horizons ranging from 1 quarter to 2 years. ${ }^{4}$

\section{Analysis and Discussion}

Our forecasts are based on lagged inflation and several combinations of lagged moments; relative price variability, relative price variability and relative price skewness, relative price skewness only, and relative price skewness $\times$ relative price variability. Ball \& Mankiw (1995) refer to the latter as an interaction term and provide further theoretical justification for considering this term for inflation forecasting.

Our best performing forecasting models are those that above inflation only include relative price skewness or relative price skewness $\times$ relative price variability, with a small advantage to the former. In contrast, forecasting models based on relative price variability or both relative price variability and skewness typically yield worse forecasts than a univariate model that is based only on inflation.

\footnotetext{
${ }^{4}$ Using autoregressive inflation models, we initially compared the direct forecasting method with the iterative method. We found that the direct method yielded, on average, $23 \%$ lower forecast errors. This finding supports our choice of forecasting method.
} 
We report mean squared error (MSE) ratios for forecast models based on skewness in Table $1 .^{5}$ These ratios suggest that models augmented with skewness typically outperform models that include only inflation. More specifically, the MSE's are lower in 46 out of 64 cases. Interestingly, the MSE's are always lower for longer forecast horizons of 1.5-2 years irrespective of lag-specification. In addition, one-sided tests based on Diebold \& Mariano (1995) often suggest that the differences are statistically significant.

\footnotetext{
${ }^{5}$ All other results are available from the authors upon request.
} 


\section{References}

Balke, N. and M. Wynne, 2000. An equilibrium analysis of relative price changes and aggregate inflation. Journal of Monetary Economics 45, 269-292.

Ball, L. and Mankiw, G., 1995. Relative-price changes as aggregate supply shocks. Quarterly Journal of Economics 110, 161-193.

Barnett, W. and A. Serletis, 1990, A dispersion-dependency diagnostic test for aggregation error: With applications to monetary economics and income distribution, Journal of Econometrics 43, 5-34.

Barro, R., 1976, Rational expectations and the role of monetary policy, Journal of Monetary Economics 2, 1-32.

Bordo, M., 1980, The effects of monetary change on relative commodity prices and the role of long-term contracts, Journal of Political Economy 88, 1088-1109.

Bryan, M. and S. Cecchetti, 1999, Inflation and the distribution of price changes, Review of Economics and Statistics 81, 188-196.

Cukierman, A., 1983, Relative price variability and inflation: A survey and further results, Carnegie Rochester Conference Series on Public Policy 19, 103-138.

Diebold F. and R. Mariano, 1995, Comparing predictive accuracy, Journal of Business and Economics Statistics 13, 253-263.

Fischer, S., 1981, Relative shocks, relative price-variability, and inflation. Brookings Papers on Economic Activity 2, 381-441.

Kücük, H and Tuğer, B., 2004. Relative price variability: The case of Turkey 1994-2002., Working Paper, Central Bank of the Republic of Turkey.

Lucas, R., 1972, Expectations and the neutrality of money, Journal of Economic Theory 4, $103-124$. 
Lucas, R., 1973, Some international evidence on output-inflation tradeoffs, American Economic Review 63, 326-334.

Marcellino, M., Stock, J., and M. Watson, 2006, A comparison of direct and iterated multistep AR methods for forecasting macroeconomic time series, Journal of Econometrics, forthcoming.

Parks, R., 1978, Inflation and relative price variability, Journal of Political Economy 86, 7996.

Sheshinski, E. and Y. Weiss, 1977, Inflation and costs of price adjustment, Review of Economic Studies 44, 287-303.

Stock, J. and M. Watson, 1999, Forecasting inflation, Journal of Monetary Economics 44, $293-335$.

Theil, H., 1967, Economics and information theory (North-Holland, Amsterdam).

Tobin, J., 1972, Inflation and unemployment, American Economic Review 62, 1-18.

Vining, D. and T. Elwertowski, 1976. The relationship between relative prices and the general price level. American Economic Review 66, 699-708. 
Table 2: MSE-Ratios

\begin{tabular}{lcccccccc}
\hline$h \backslash k$ & 1 & 2 & 3 & 4 & 5 & 6 & 7 & 8 \\
\hline 1 & 99.87 & $\underline{90.57}$ & $\underline{93.86}$ & 109.17 & 109.39 & 108.84 & 103.88 & 108.93 \\
2 & $\underline{91.15}$ & $\underline{92.15}$ & 111.43 & 116.43 & 115.74 & 102.00 & 99.41 & 99.61 \\
3 & 100.74 & 109.01 & 119.43 & 125.28 & 103.81 & 95.32 & 89.91 & $\underline{78.66}$ \\
4 & 103.82 & 111.77 & 119.22 & 95.89 & $\underline{86.19}$ & $\underline{81.01}$ & $\underline{69.14}$ & $\underline{85.31}$ \\
5 & 102.27 & 99.96 & $\underline{88.76}$ & $\underline{84.36}$ & $\underline{78.57}$ & $\underline{67.03}$ & $\underline{64.83}$ & $\underline{69.63}$ \\
6 & $\underline{96.42}$ & $\underline{82.85}$ & $\underline{80.38}$ & $\underline{78.54}$ & $\underline{66.63}$ & $\underline{64.22}$ & $\underline{57.76}$ & $\underline{71.02}$ \\
7 & $\underline{91.28}$ & $\underline{80.74}$ & $\underline{81.89}$ & $\underline{71.32}$ & $\underline{68.45}$ & $\underline{61.77}$ & $\underline{63.15}$ & $\underline{70.72}$ \\
8 & $\underline{93.68}$ & $\underline{90.11}$ & $\underline{82.03}$ & $\underline{77.80}$ & $\underline{76.61}$ & $\underline{79.49}$ & $\underline{88.86}$ & $\underline{86.35}$ \\
\hline
\end{tabular}

Note: MSE-ratios are calculated as follows for each lag structure and forecast horizon: $100 \times$ MSE(model that includes skewness)/MSE(model that only includes inflation). Underlined ratios indicate that we reject the null hypothesis that the two forecasts are equal at the 5\% significance level using a one-sided Diebold Mariano (1995) test. 
Figure 1. Inflation, relative price variability and skewness
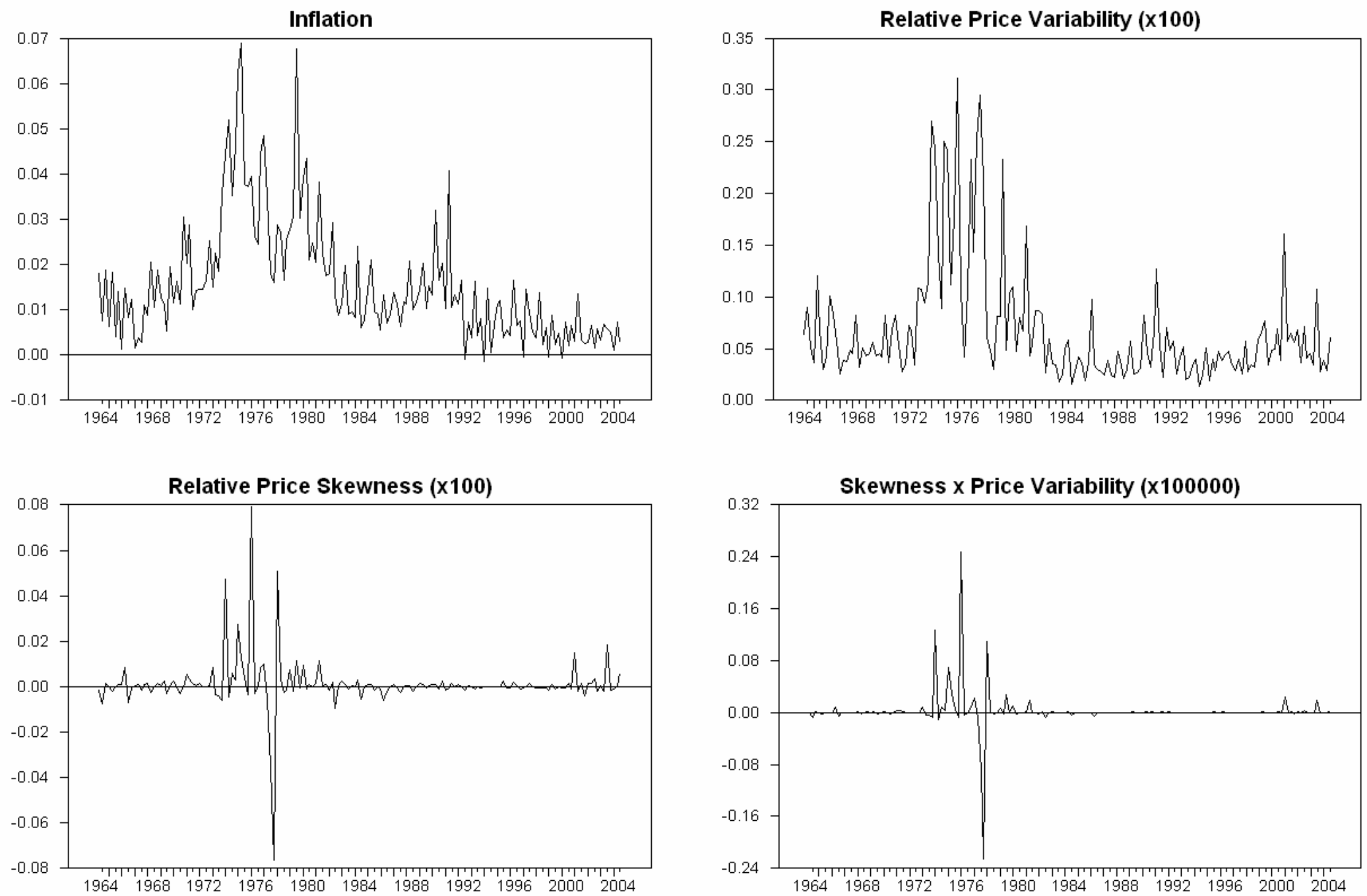